\title{
Mechanical and Ballistic Property Variations of a Solid Propellant During Accelerated Ageing
}

\author{
Kadiresh P N ${ }^{1} \&$ Sridhar B T N ${ }^{2}$ \\ ${ }^{1} \mathrm{PhD}$ Scholar, ${ }^{2}$ Assiatant Professor \\ MIT Campus, Anna University, Chennai, India \\ e-mail: kadiresh71@gmail.com
}

\begin{abstract}
In this paper the ageing behaviour of a composite solid propellant has been described by measuring its mechanical and ballistic properties at regular intervals during an accelerated ageing period. The solid propellant consists of Ammonium Perchlorate (AP), Hydroxyl Terminated Poly Butadiene (HTPB), Aluminium (Al) and ballistic modifiers, burning rate catalyst and other additives. Propellant blocks were aged at constant relative humidity of $50 \%$ at three different storage temperatures 70,60 and $55 \mathrm{oC}$. The mechanical test conducted on the propellant was uniaxial tension test. The mechanical properties measured in the tension test were Young's modulus, breaking stress and percentage of elongation at the time of break. The propellant ballistic properties like burning rate and burning rate exponent were also determined during the ageing period from the ballistic tests. From this study it is observed that burning rate at low pressures did not undergo significant changes during the ageing period but the changes in Young's modulus and relaxation modulus were significant.
\end{abstract}

Key words: AP-HTPB based solid Propellant, Burning rate, Ageing behaviour.

\section{I.INTRODUCTION}

The ageing behaviour of composite solid propellants is well documented in the literature $[1,2,3,4]$. This paper aims at studying the ageing behaviour of a composite propellant with a specific composition (CASR-CSP1) containing AP, HTPB, Al and the other ingredients like ballistic modifier, burning rate catalyst, additives etc. Though it is known that ballistic properties do not undergo major changes [4], this was sought to be verified for the above composition. Preliminary studies involving both mechanical and ballistic tests were conducted on the propellant composition to understand the ageing behaviour. The changes in modulus, percentage of elongation, burning rate, ignition delay time and other properties were experimentally measured at regular intervals during the course of an accelerated ageing period.

\section{EXPERIMENTATION}

In all the accelerated ageing programs of this investigation the relative humidity was maintained at $50 \%$ for the propellant blocks in a climatic chamber. The accelerated ageing was carried out at three different elevated temperatures of 70,60 and $550 \mathrm{C}$ till $50 \%$ change in one or more of the properties were noticed. Temperatures above $700 \mathrm{C}$ were not attempted as too high values might activate mechanisms which are not present under normal operating conditions [5]. Samples were drawn at regular intervals and specimens were made. The specimens were then conditioned in desiccators for one day at $40 \% \mathrm{RH}$. Specimen conditioning is important before carrying out test because that would ensure uniform pretest conditions for all specimens to be tested so that the data obtained from the experiments is not affected by pretest conditions. The test specimens in dumbbell shape were prepared as per the ASTM D412C standards for uniaxial tension tests [6]. The thickness of the specimens was $6 \mathrm{~mm}$. The test specimen was mounted in a computer controlled universal testing machine and the tests were conducted at cross head speeds of $50 \mathrm{~mm} /$ minute.

Propellant strands of dimensions $5 \mathrm{~mm} \times 5 \mathrm{~mm} \times$ $100 \mathrm{~mm}$ with insulation coating on four sides were tested in a strand burner in the inert atmosphere of nitrogen at different pressures ranging from 1 to 50 bar. The burning rate was determined by conventional fuse wire and timer technique. Ignition delay tests were conducted using a micro-thermocouple technique. A Pt / Pt- $13 \% \mathrm{Rh}$ thermocouple of 40 micron hot junction diameter was trapped between two propellant strips of dimensions $25 \mathrm{~mm} \times 10 \mathrm{~mm} \times 6 \mathrm{~mm}$ such that the hot junction coincided with the propellant surface. The online data acquisition from thermocouple gave the ignition delay time.

\section{ANALYSIS OF RESULTS}

The results from mechanical and ballistic tests are presented in the form of plots in Figures 1 through 6 . The variation of Young's Modulus with ageing time under three different accelerated ageing conditions (store temperatures 70,60 and $55 \mathrm{oC}$, all at constant relative humidity of $50 \%$ ) is shown in Fig. 1 . 


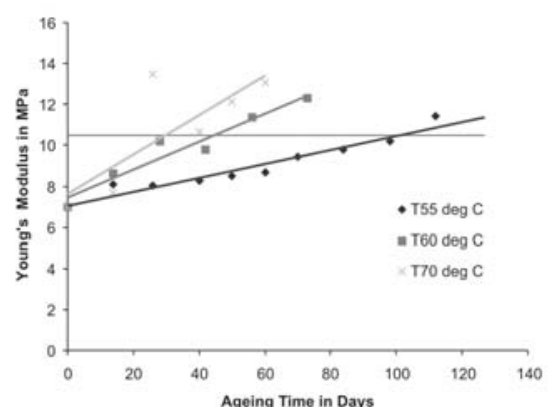

Fig. 1. Variation of Young's Modulus with Accelerated Ageing Days

The increase in modulus is about $50 \%$ though the ageing time under the three ageing conditions for this change is different. In Fig. 2, variation of breaking stress with accelerated ageing days is shown. The percentage of elongation up to break also varies linearly with ageing time and this variation is shown in Fig. 3 . The reduction in percentage of elongation at $55 \mathrm{OC}$ over a period of 113 days is about $10 \%$, whereas at $70 \mathrm{oC}$, it is $25 \%$ over 63 days.

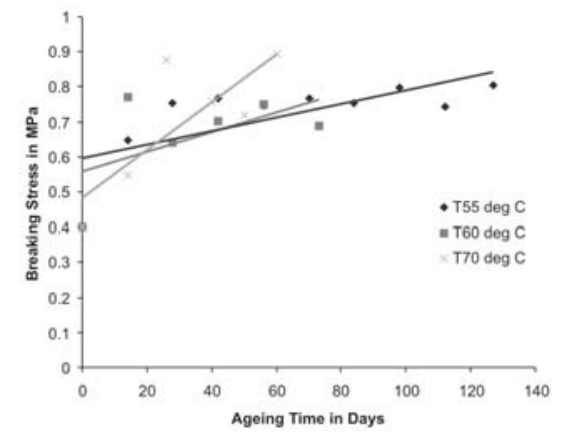

Fig. 2. Variation of Breaking Stress with Accelerated Ageing Days.

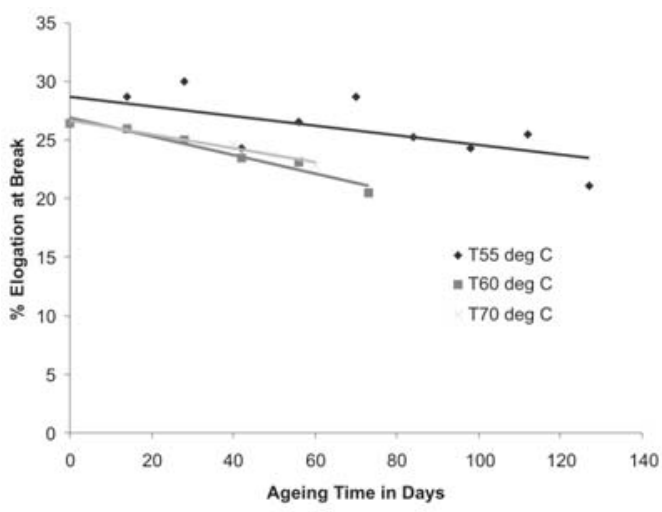

Fig. 3 Variation of \% Elongation at Break with Accelerated Ageing Days
From the above variations of properties with respect to ageing time, it can be concluded that percentage of elongation at break changed only by less than $10 \%$ at different store temperatures. However, Young's modulus changed significantly with ageing time $[7,8]$.

The results of ballistic tests during the ageing period are presented here. Pressure Burning rate plots for both aged and unaged propellants are shown in Fig. 4. From the figure it can be observed that the burning rate exponent for aged propellant is slightly higher (increases by $10 \%$ ). But the burning rate at lower pressures ( $<10 \mathrm{~atm}$ ) is relatively unaffected.

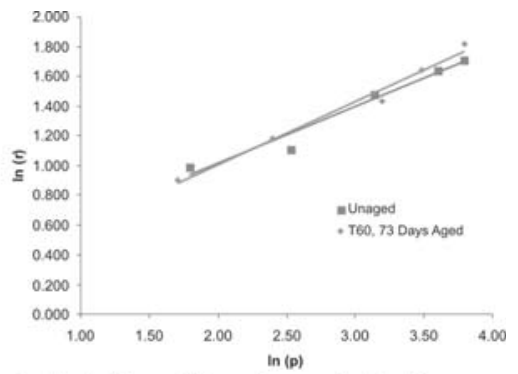

Fig. 4. Variation of Burning rate Vs Pressure on Logarithmic Scale for Aged and Unaged Propellants.

The behaviour of burning rate with ageing time is shown in Fig. 5. The burning rate tests were carried out at $1 \mathrm{~atm}$ pressure in nitrogen gas environment. From the figure it can be noticed that the change in burning rate due to ageing is less than $1 \%$.

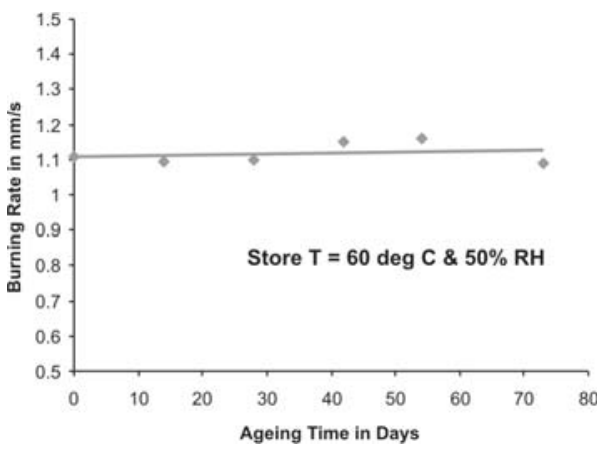

Fig. 5. Variation of Burning Rate Vs Ageing Time at $1 \mathrm{~atm}$ Pressure

Ignition delay tests were also carried out on aged samples using a micro-thermocouple technique. The behaviour of ignition delay with respect to ageing time is shown in Fig. 6. Again it can be seen from the figure that ageing does not seem to have any appreciable effect on ignition delay. The change in ignition delay time is less than $5 \%$ within the scatter of the data [9]. 


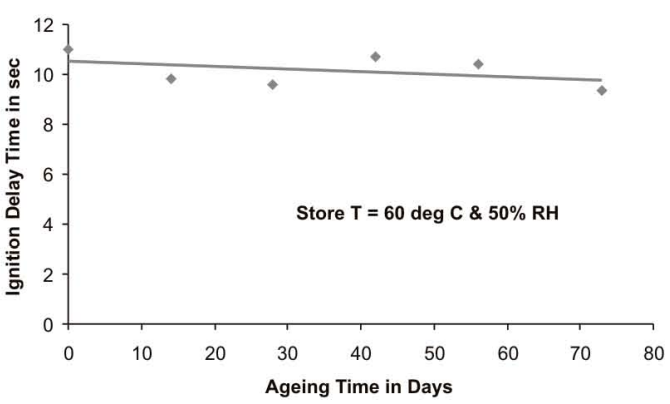

Fig. 6 Variation of Ignition Delay Time Vs Agening Time

\section{CONCLUSION}

The following conclusions are made from this investigation. Young's modulus varied by $50 \%$ during the ageing period of this investigation, whereas the variations in percentage of elongation is relatively small. Ageing causes micro-cracks near the interfaces of binder and the solid particles of the propellant. At low pressures, burning rate did not show any significant change and the change was less than $1 \%$. But at higher pressures (>10 atm), there was some noticeable change.

\section{REFERENCES}

[1] Bills K. W., DePree D. O., Mc.Camey R. K. and Smith R. M. "The Chemical Kinetic Approach to Service Life Prediction of Propellant Systems", AIAA/SAE/ASME 15th Joint Propulsion Conference, 1979, LasVegas, Nevada, 79-1243.

[2] Carlos Schuler and Jose Luis de la Fuente "Ageing Studies on HTPB Propellants by Dynamic Mechanical Analysis" Paper presented at the AGARD PEP Symposium on "Service Life of Solid Propellant Systems" held in Athens, Greece, 10 14, May 1996.
[3] Jenaro G., Ray F., de la Cruz and Perez V., "Ageing Behaviour of Composite Propellants" Paper presented at the AGARD PEP Symposium on "Service Life of Solid Propellant Systems" held in Athens, Greece, 10 14, May 1996.

[4] Christiansen, A. G., Layton L. H. and Carpenter, R. L, "HTPB PropellantAgeing" Journal of Spacecraft, Vol. No. 18, No. 3, May June 1981, pp. 211215.

[5] Keizers H. L. J and Miedema J. R., "Structural Service Lifetime Modelling For Solid Propellant Rocket Motors" Paper presented at the AGARD PEP Symposium on "Service Life of Solid Propellant Systems" held in Athens, Greece, 10 14, May 1996.

[6] ASTM Standard D3183-84, Standard Practice for Rubber Preparation of Pieces for Test Purposes from Products, Annual Book of ASTM Standards, Vol. 09.01, 2003.

[7] Cunliffe A. V., Davis A. and Tod D., "Ageing and Life Prediction of Composite Propellant Motors", Paper presented at the AGARD PEP Symposium on "Service Life of Solid Propellant Systems" held in Athens, Greece, 10 14, May 1996.

[8] B Dao, J Hodgkin, J Krstina, J Mardel, W Tian, "Accelerated Ageing Versus Realistic Aging in Aerospace Composite Materials. III. The Chemistry of Thermal Ageing in Bismaleimide Based Composites", Journal of Applied Polymer Science, Vol. 105, Pages 2062 2072, 2007.

[9] Senthil M, Saravanmoorthy V, Sridhar BTN, Rajaram Nagappa, "Ageing Behaviour of Aluminized APHTPB Composite Propellant at Elevated Temperature", paper presented at HEMCE conference, 2005, held in Hyderabad, India 